\title{
PRODUÇÃO DE MILHO, TRIGO E SOJ A EM FUNÇÃO DAS ALTERAÇÕES DAS CARACTERÍSTICAS QUÍMICAS DO SOLO PELA APLICAÇÃO DE CALCÁRIO E GESSO NA SUPERFÍCIE, EM SISTEMA DE PLANTIO DIRETO(1)
}

\author{
E. F. CAIRE $S^{(2)}, A . F . F O N S E C A^{(3)}, J$. MENDE $S^{(3)}$, \\ W. A. CHUEIRI ${ }^{(4)} \&$ E. F. MADRUGA ${ }^{(5)}$
}

\begin{abstract}
RESUMO
0 experimento foi realizado em um Latossolo Vermelho-E scuro distrófico textura média, em Ponta Grossa (PR), com o objetivo de avaliar a produção de milho, trigo e soja em função das alterações das características químicas do solo, pela aplicação de calcário e gesso na superfície, em sistema plantio direto. O delineamento experimental empregado foi o de blocos ao acaso em parcela subdividida, com três repetições. Foram utilizadas quatro doses de calcário dolomítico, com 84\% de PRNT: 0, 2, 4 e $6 \mathrm{t} \mathrm{ha-1}$ e quatro doses de gesso agrícola: 0 , 4, 8 e $12 \mathrm{t} \mathrm{ha}^{-1}$. A calagem foi realizada em julho, e a aplicação de gesso feita em novembro de 1993. A produção da cultura de mi lho foi avaliada no ano agrícola de 1994/95, a de trigo no inverno de 1996 e a de soja em 1996/97. A aplicação de calcário na superfície não influenciou a produção de milho, trigo e soja. Houve ação da calagem na correção da acidez de camadas superficiais e do subsolo, porém seu efeito em camadas profundas não foi observado após quarenta meses. O gesso foi eficiente na mel horia do ambiente radicular do subsolo, embora tenha causado lixiviação de magnésio trocável do solo. Das três culturas avaliadas, somente o milho apresentou resposta à aplicação de gesso em decorrência do fornecimento de enxofre, da melhoria do teor de cálcio trocável, da redução da saturação por alumínio e do aumento da relação $\mathrm{Ca} / \mathrm{Mg}$ do solo.
\end{abstract}

Termos de indexação: calagem, subsolo, acidez, lixiviação de íons.

\footnotetext{
(1) Recebido para publicação em abril e aprovado em outubro de 1998.

(2) Professor do Departamento de Ciência do Solo e Engenharia Agrícola, Universidade Estadual de Ponta Grossa - UEPG. Caixa Postal 992/3, CEP 84010-330 Ponta Grossa (PR). E-mail: efcaires@uepg.br Bolsista do CNPq.

(3) Bolsista do PIBIC-CNPq/UEPG

(4) Engenheiro-Agrônomo, aluno do curso de Mestrado em Ciência do Solo, Universidade Federal do Paraná. Caixa Postal 2959, CE P 80035-050 Curitiba (PR).

(5) Engenheiro-Agrônomo, MSc, aluno do curso de Doutorado em Solos e Nutrição de Plantas, Escola Superior de Agricultura Luiz de Queiroz - ESALQ/USP. E-mail: efmadrug@carta.ciagri.usp.br.
} 


\author{
SUMMARY: CORN, WHEAT AND SOYBEAN YIELDS AS A FUNCTION OF \\ THE CHANGES IN SOIL CHEMICAL CHARACTERISTICS DUE \\ TO SURFACE APPLICATION OF LIME AND GYPSUM UNDER \\ A NO-TILLAGE SYSTEM
}

\begin{abstract}
This experiment was carried out on a dystrophic Dark-Red Latosol from Ponta Grossa, Paraná, Brazil, to evaluatetheyield of corn, wheat and soybean as a function of thechanges in thechemical characteristics of soil dueto surface application of lime and gypsum under a no-tillagesystem. A completely randomized block design was used, with threreplications, in a split-plot experiment. Dol omitic limestone was applied at rates of $0,2,4$ and $6 \mathrm{t} \mathrm{ha}^{-1}$ (main plots) in J uly of 1993; gypsum was applied at rates of 0, 4, 8 and $12 \mathrm{t} \mathrm{ha}^{-1}$ (subpl ots) in N ovember of 1993. Corn was evaluated in the agricultural year of 1994/ 1995, wheat in the winter of 1996 and soybean in 1996/ 1997. Liming did not influence corn, wheat and soybean yields. Although limeacted upon thesurfacecorrecting theacidity of thesuperficial layers and subsoil, its effect in deep layers was not observed after 40 months. Gypsum improved the chemical characteristics of the subsoil, although it caused leaching of exchangeable magnesium of the soil. Of the three cultures studied, only corn responded to gypsum application, due to sulfur supply, the improvement of exchangeable calcium, the reduction of aluminum saturation and increased $\mathrm{Ca} / \mathrm{Mg}$ relationship in soil.
\end{abstract}

Index terms: liming, gypsum, subsoil, acidity, ion leaching, no-tillagesystem.

\section{INTRODUÇÃO}

O sistema plantio direto ("no-tillage system") tem apresentado rápido crescimento no Brasil nesta última década, com estimativa de cultivo de seis milhões dehectares (Wiethölter, 1997), na safra 1996/ 97. Entretanto, os aspectos relacionados com a fertilidade do solo, neste sistema, nem sempre são os mesmos aplicados para o sistema convencional de manejo. Y oung, em 1982, alertava para ofato dequeo manejo da calagem e da adubação nosistema convencional não seria apropriado para o sistema de plantio direto (Young, 1982 citado por Wiethölter, 1997).

Há evidências de que a necessidade de calcário no sistema de plantio direto seja menor do que no sistema convencional de preparo (Pöttker, 1996; Phillips \& Phillips, 1984 citados por Wiethölter, 1997). Todavia, faltam informações a respeito da reação do cal cário aplicado na superfície do solo, em sistema plantio direto, bem como das conseqüências das alterações das características químicas do solo, pela calagem superficial, sobre a nutrição mineral e produção das culturas em rotação.

Como no plantio direto a calagem é realizada na superfície, espera-seuma ação do cal cário muito mais lenta e restrita às camadas superficiais do solo, em comparação à do sistema convencional de preparo, em que o cal cário é incorporado.

As limitações causadas pela acidez do subsolo à produtividade agrícola, devidas à restrição ao crescimento radicular e à absorção de água e nutrientes pelas culturas, têm sido amplamente divulgadas na literatura (Pavan et al., 1982; Ritchey et al., 1982; Sumner et al., 1986; Farina \& Channon, 1988). Entretanto, as implicações da manutenção de subsolo ácido sobre o desenvolvimento e sobre a produção das culturas no sistema plantio direto têm sido pouco estudadas.

Por ser relativamente solúvel (Bolan et al., 1991 citados por Sumner, 1995), o gesso agrícola aplicado na superfície do sol o movimenta-se ao longo do perfil sob influência do excesso de umidade. Como conseqüência, obtêm-se aumento no suprimento de cál cio e redução da toxidez de alumínio no subsolo (Sumner, 1995). Os efeitos positivos do gesso agrícola observados nas mais variadas condições de solo e clima (Pavan et al., 1984; N ogueira, 1985; Sumner et al ., 1986; Farina \& Channon, 1988) são indicativos de que o seu emprego pode também constituir boa alternativa para a mel horia do ambiente radicular do subsol o em sistemas de cultivo que não envolvem o preparo do solo.

O presente trabal ho objetivou avaliar a correção da acidez do solo mediante calagem na superfície, os efeitos da aplicação superficial de gesso sobre o subsolo ácido e as conseqüências dessas alterações sobre a produção de milho, trigo e soja cultivados em rotação no sistema de plantio direto.

\section{MATERIAL E MÉTODOS}

O experimento foi realizado no município de Ponta Grossa (PR), Fazenda Estância dos Pinheiros, 
em um Latossolo Vermelho-E scuro distrófico textura média, há quinze anos sob plantio direto. Os resultados da análise química do solo, realizada antes da instalação, estão apresentados no quadro 1. O delineamento experimental empregado foi o de blocos ao acaso em parcelas subdivididas, com três repetições. Os tratamentos foram constituídos por quatro doses de calcário dolomítico, com $84 \%$ de poder relativo de neutralização total (PRNT): 0, 2, 4 e $6 \mathrm{t}$ ha-1, visando el evar a saturação por bases (V\%) da camada de 0-20 cm desoloa 50, 70 e90\%, equatro doses de gesso agrícola: 0, 4, 8 e 12 t ha-1, equi valentes em cálcio às doses decal cário. $\mathrm{O}$ cal cário foi aplicado, nas parcelas principais, em julho, e o gesso, nas subparcelas, em novembro de 1993, sendo ambas as aplicações feitas a lanço na superfície do solo.

As parcelas, com 6,3 m de largura e $32,0 \mathrm{~m}$ de comprimento, receberam os tratamentos de cal agem. Estas foram divididas em quatro subparcelas de 8,0 m de comprimento, recebendo as doses de gesso. Na rotação de culturas, foram utilizados: soja (1993/ 94), aveia-preta/ervilhaca (inverno/94), milho (1994/ 95), pousio (inverno/95), soja (1995/96), trigo (inverno/ 96) e soja (1996/97). A resposta da cultura da soja nos anos de 1993/94 e 1995/96 foi avaliada em outro trabal ho (Caires et al., 1998).

A semeadura do milho, híbrido Cargill 901, foi feita em 24 de novembro de 1994, na densidade de cinco sementes por metro linear e espaçamento de 0,9 m entrelinhas. A adubação básica utilizada na semeadura foi de $250 \mathrm{~kg} \mathrm{ha}^{-1}$ da fórmula 8-28-16 e, em cobertura, foram aplicados $45 \mathrm{~kg} \mathrm{ha}-1$ de nitrogênio, na forma de uréia. Para avaliar a produção de grãos de milho, foram col hidas as três linhas centrais por seis metros de comprimento em cada subparcela, tendo sido desprezado um metro de cada extremidade.

Em 18 dejunho de 1996, foi efetuada a semeadura do trigo, cultivar Embrapa 16, no espaçamento de 0,15 m entrelinhas e população de 2.230 .000 plantas por hectare. Na adubação de semeadura, utilizou-se a dose de $250 \mathrm{~kg} \mathrm{ha}-1$ da fórmula $5-25-25$ e $45 \mathrm{~kg}$ ha-1 denitrogênio, na forma de uréia, em cobertura. Para avaliar a produção de grãos de trigo, foram col hidas as vinte linhas centrais por quatro metros de comprimento em cada subparcela, tendo sido desprezados dois metros de cada extremidade.

O cultivo da soja, cultivar FT 5 (Formosa), foi feito em 10 de dezembro de 1996, na densidade de vinte sementes por metrolinear e espaçamento de 0,45 m entrelinhas, com adubação de semeadura à base de 48 kg ha-1 de $\mathrm{K}_{2} \mathrm{O}$, na forma de cl oreto de potássio. Para avaliar a produção de grãos de soja, foram colhidas as seis linhas centrais por quatro metros de comprimento em cada subparcela, tendo sido desprezados dois metros de cada extremidade.

Foram coletadas amostras de solo aos 18 e 40 meses após a calagem, correspondendo a 14 e 36 meses da aplicação de gesso, uma vez que este fora aplicado quatro meses após o cal cário. As amostragens foram realizadas durante o crescimento do milho e logo após a col heita do trigo, retirando-se 12 subamostras por subparcela, para compor uma amostra composta das camadas de 0-5, 5-10 e 10-20 cm, e cinco subamostras para as camadas de 20-40, 40-60 e $60-80 \mathrm{~cm}$ de profundidade. As amostras até a profundidade de $20 \mathrm{~cm}$ foram coletadas com trado calador, eas de $20-80 \mathrm{~cm}$, com trado hol andês, tendo si do determi nados o pH, $\mathrm{H}+\mathrm{Al}, \mathrm{Al}^{3+}$ e cátions básicos pel os métodos descritos em Pavan et al. (1991). Nas amostras de solo coletadas a 40 meses após a calagem e 36 meses após a aplicação de gesso, foram determinados também os teores deS-SO ${ }_{4}^{2-}$, mediante extração pelo acetato de amônio 0,5 mol L-1 em ácido acético $0,25 \mathrm{~mol} \mathrm{~L}^{-1}$ e posterior quantificação pelo método turbidimétrico, descrito por Vitti \& Suzuki (1978).

Amostras de folhas foram coletadas em 30 plantas de cada subparcela. Na cultura do mil ho, a amostragem foi realizada por ocasião da antese plena, retirando-se a fol ha imediatamente abaixo e oposta à espiga. No trigo, foi col hida toda a parte aérea da primeira à quarta folha a partir do ápice das plantas, por ocasião do início do florescimento. No caso da soja, foram col etadas as terceiras fol has a partir do ápice das plantas, também no início do florescimento. Essas amostras foram lavadas em

Quadro 1. Resultados de análise química do solo antes da instalação do experimento em diferentes profundidades

\begin{tabular}{|c|c|c|c|c|c|c|c|c|c|c|}
\hline Profundidade & $\begin{array}{c}\mathrm{pH} \\
\left(\mathrm{CaCl}_{2}\right)\end{array}$ & $\mathbf{H}+\mathbf{A l}$ & $\mathrm{Al}^{3+}$ & $\mathrm{Ca}^{2+}$ & $\mathrm{Mg}^{2+}$ & $\mathbf{K}^{+}$ & P (Mehlich-1) & C & $\mathbf{V}^{(\mathbf{1})}$ & $\mathrm{m}^{(2)}$ \\
\hline $\mathrm{cm}$ & & 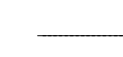 & $n$ & $\mathrm{ol}_{\mathrm{c}} \mathrm{dm}$ & 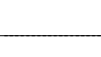 & - & $\mathrm{mg} \mathrm{dm} \mathrm{m}^{-3}$ & $\mathrm{~g} \mathrm{dm}^{-3}$ & $\longrightarrow$ & - \\
\hline $0-20$ & 4,5 & 58 & 6 & 16 & 10 & 1,4 & 9 & 19 & 32 & 18 \\
\hline $20-40$ & 4,4 & 58 & 6 & 16 & 10 & 1,5 & 4 & 18 & 32 & 18 \\
\hline $40-60$ & 4,4 & 50 & 6 & 16 & 9 & 1,5 & 2 & 16 & 34 & 18 \\
\hline
\end{tabular}

(1) $\mathrm{V}$ = saturação por bases. ${ }^{(2)} \mathrm{m}$ = saturação por alumínio. 
água desionizada, colocadas para secar em estufa com circulação forçada de ar a $60^{\circ} \mathrm{C}$, até atingirem peso constante, e posteriormente moídas. Foram analisados os teores de Ca, Mg e S pelos métodos descritos em Malavolta et al. (1989).

A análise de variância seguiu o modelo em parcel as subdivididas. $\mathrm{Na}$ ausência de significância da interação calcário x gesso sobre as variáveis estudadas, os efeitos principais da calagem e do gesso foram discutidos separadamente, utilizando-se a média dos tratamentos.

Mediante análises de regressão por polinômios ortogonais foram ajustadas equações aos dados obtidos em função das doses de cal cário e de gesso utilizadas. Consideraram-se apenas as regressões de coeficientes de determinação significativos a 5\%. As análises estatísticas foram executadas por meio de programa de computador ESTAT, conforme método descrito por Banzato \& Kronka (1989).

\section{RESULTADOS E DISCUSSÃO}

A aplicação de calcário na superfície, após 18 meses ( $F$ igura 1 ), proporcionou aumento do $\mathrm{pH}$ até $10 \mathrm{~cm}$ de profundidade e também nas camadas mais profundas do solo $(40-60$ e $60-80 \mathrm{~cm})$. Considerando a baixa solubilidade do calcário e a mobilidade limitada dos produtos de sua reação no solo, em princípio, não era esperado tal efeito. Redução da acidez do solo, até $40 \mathrm{~cm}$ de profundidade, após 32 meses da aplicação de cal cário na superfície, em sistema plantio direto, foi observada por Oliveira \& Pavan (1994). De acordo com esses autores, houve movimentação física do cal cário em profundidade, provavelmente por meio de canais formados por raízes mortas, mantidos intactos dada a ausência de preparo do sol o. A ausência de efeito da calagem sobre o $\mathrm{pH}$ nas camadas de 10-20 e $20-40 \mathrm{~cm}$ indica, entretanto, que não deve ter
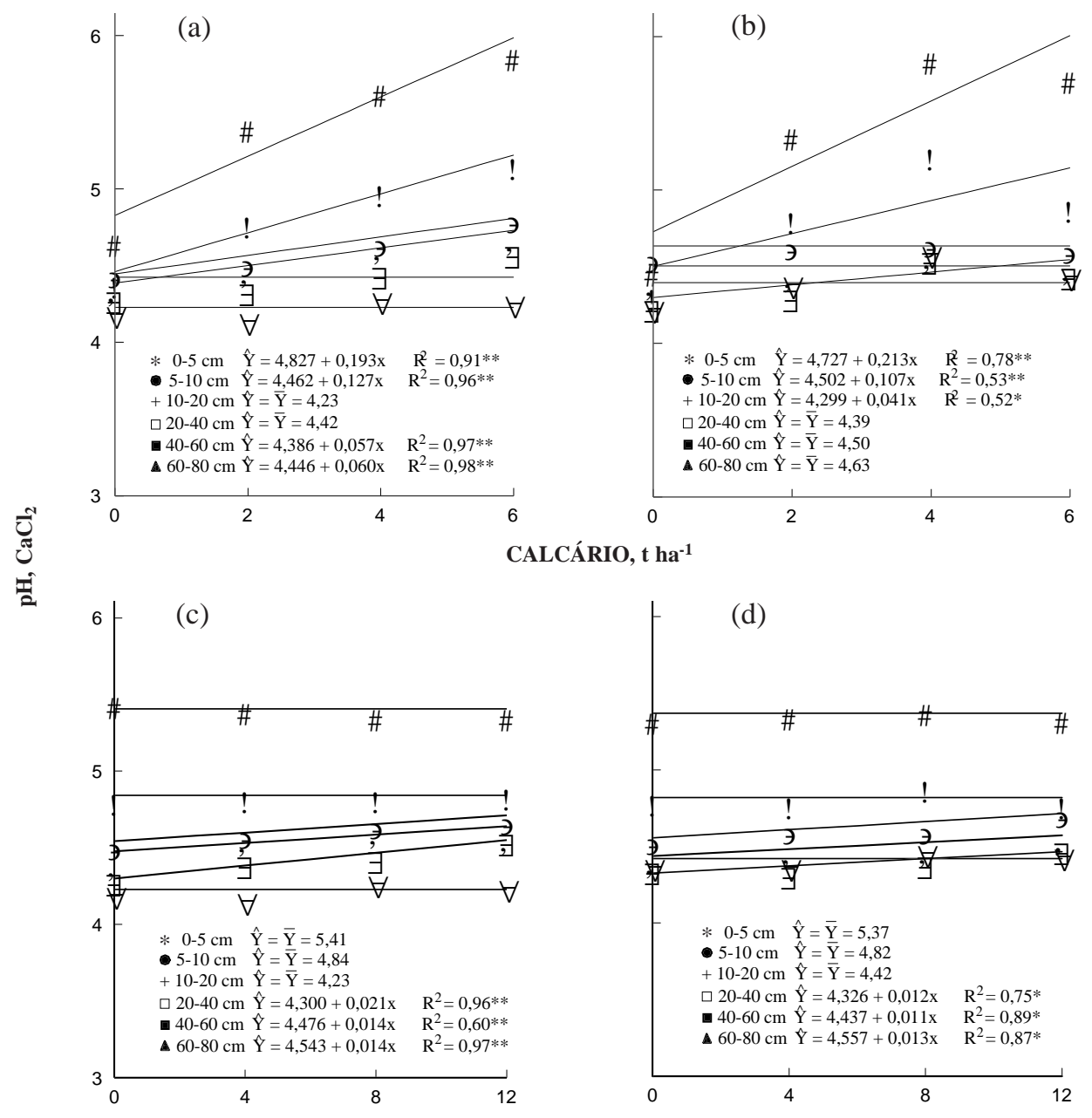

CALCÁRIO, $\mathrm{t} \mathrm{ha}^{-1}$

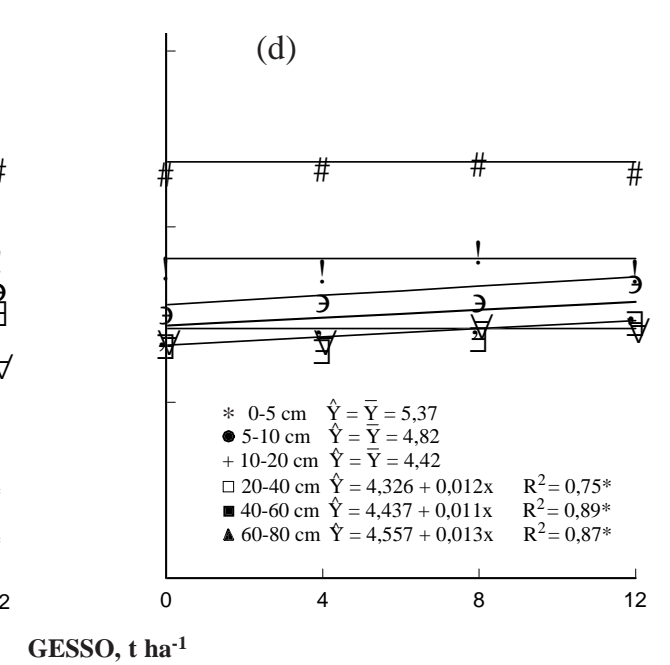

Figura 1. E feito de doses de calcário, após 18(a) e 40(b) meses, e de gesso, após 14(c) e 36(d) meses, nos valores de pH , em diferentes profundidades. (a e b: médias de quatro doses de gesso; c e d: médias de quatro doses de calcário). *, ** significativos a 5 e 1\%, respectivamente. 
ocorrido movimentação física do cal cário, devendoa el evação do pH em camadas mais profundas do solo ser atribuída a outros fatores. Raij et al. (1988) verificaram redução da acidez do sol o motivada pela absorção de nitratos, pel o sorgo, devida à chamada absorção alcalina. Acredita-se que a redução da acidez do subsolo possa ter sido provocada, pelo menos em parte, por reações dependentes da nitrificação, mediantelixiviação de nitratos de cál cio e magnésio para camadas mais profundas, com maior absorção denitratos no subsolo. Ressalte-seque, nessa amostragem, as amostras de solo foram retiradas das entrel inhas da cultura do milho, após a aplicação de nitrogênio em cobertura. Após 40 meses, apesar de o cal cário continuar apresentando reação no sol o, revelada pela el evação do pH atéa profundidade de $20 \mathrm{~cm}$, seu efeito no subsolo não foi mais observado, mostrando-se não muito duradouro.

A aplicação de gesso não exerceu influência sobre a acidez nas camadas superficiais, mas causou el evação do pH no subsolo o (20-40, 40-60 e 60-80 cm), efeito observado aos 14 e 36 meses de sua aplicação no solo (Figura 1). É provável que tal efeito se deva a uma reação de troca de ligantes na superfície das partículas de solo, envolvendo óxidos hidratados de ferroealumínio, com o $\mathrm{SO}_{4}{ }^{2-}$ deslocando $\mathrm{OH}^{-}$e, assim, promovendo neutralização parcial da acidez (Chang \& Thomas, 1963; Raij et al.,1988).

Os teores de alumínio trocável também foram reduzidos pela calagem (Figura 2), após 18 meses, até $10 \mathrm{~cm}$ de profundidade e nas camadas subsuperficiais (20-40, 40-60 e 60-80 cm). Deforma semel hante ao ocorrido para o valor pH, a redução dos teores de alumínio trocável pela calagem em camadas profundas não teve efeito muito duradouro, pois tal efeito não foi mais observado após 40 meses. A redução dos teores de $\mathrm{Al}^{3+}$ em profundidade, pela calagem realizada na superfície, pode estar relacionada com o mecanismo de lixi viação de cál cio proposto por Miyazawa et al. (1996) ecom a formação de complexos orgâni cos hidrossolúveis presentes nos restos das plantas. Na camada superficial do solo, os ligantes orgânicos complexam o cál cio trocável, formando complexos CaL ${ }^{0}$ ou CaL ${ }^{-}$. A alteração da carga do $\mathrm{Ca} 2+$ facilita sua mobilidade no solo. $\mathrm{Na}$ camada subsuperficial, o cálcio dos complexos Ca-orgânicos é desl ocado pelo al umínio trocável do solo, porque os íons $\mathrm{Al}^{3+}$ formam complexos mais estáveis que os $\mathrm{Ca}_{2}^{2+}$, diminuindoa acidez trocável e aumentando o cálcio trocável. Embora o efeito da calagem na superfície sobre os teores de alumínio trocável no subsolo também tenha sido observado por Caires et al. (1998), após 28 meses, a estabilidade desses complexos orgânicos poderia ser questionada, por não ter sido constatado este efeito após 40 meses.

De acordo com Hue et al.(1986), o grau de amenização da toxidez de alumínio depende principalmente da concentração e da estabilidade do complexo formado. Os ácidos que possuem grupos $\mathrm{RCOCOO}^{-}, \mathrm{RCOCH}_{2} \mathrm{COO}^{-}, \mathrm{RCO}_{-} \mathrm{HCOO}^{-}$e
$\mathrm{RCOHCH}_{2} \mathrm{COO}^{-}$formam complexos mais estáveis com o alumínio, do tipo anel com 5 ou 6 átomos. 0 complexo Al-liganteserá mais estável quanto maior for onúmerodessetipodeligação (Miyazawa etal., 1992).

Ácidos orgânicos naturais, como cítrico e oxálico, formam complexos estáveis, enquanto o ácido fórmico, maléico, acético e succínico formam complexos de baixa estabilidade com o alumínio. Estudos da composição química da sol ução de vários solos do Alabama revelaram a presença do ácido oxálico, cítrico, málico, malônico, succínico, lático, fórmico e fitálico, em concentração total variando de 0,80 a $480 \mathrm{mmol} \mathrm{L}^{-1}$ (Hue et al., 1986). Essa variação na concentração dos ácidos orgânicos foi atribuída à atividade microbial nos diferentes manejos dos solos estudados.

Houve redução dos teores de alumínio trocável (5-10, 20-40, 40-60 e 60-80 cm, após 14 meses, e 20-40 e 40-60 cm, após 36 meses), por meio da aplicação de doses de gesso (Figura 2). Algumas hipóteses, descritas por Raij (1992), têm sido sugeridas para explicar o mecanismo envol vido. U ma delas seria a liberação de $\mathrm{OH}^{-}$pelo $\mathrm{SO}_{4}{ }^{2-}$, mediante troca de ligantes, com a formação de estruturas hidroxiladas de alumínio, mecanismo chamado por Reeve \& Sumner (1972) de "autocalagem". A precipitação de alumínio, com formação de minerais (Adams \& Rawayfih, 1977), também tem sido indicada. Outra possibilidade seria a lixiviação de alumínio acompanhando o gesso, o que pode ser, em parte, favorecido pela formação de pares iônicos ou complexos como AlSO ${ }_{4}$ (Singh, 1982; Oates \& Caldwell, 1985), ou defluoreto deal umínio (Pol omski et al., 1982; Oates \& Caldwell, 1985). E mbora ocorra redução variável de alumínio com a utilização de gesso, ainda não é possível explicar totalmente os mecanismos envolvidos (Alva et al., 1990).

A figura 3 mostra os efeitos dos tratamentos com cal cário e gesso nos teores de cál ci o trocável do solo, em diferentes profundidades. A calagem, após 18 meses, proporcionou aumento do cálcio trocável até a profundidade de $10 \mathrm{~cm}$ e no subsolo $(60-80 \mathrm{~cm})$. Tal aumento no subsol o deve ter ocorrido de acordo com o mecanismo sugerido por Miyazawa et al. (1996). Ressalta-se que, como essa amostragem foi realizada nas entrelinhas da cultura do milho, após a aplicação de nitrogênio em cobertura, pode ter ocorrido também lixiviação de cál cio para o subsolo acompanhado pelo íon nitrato. De qualquer forma, este efeito não foi mais observado 40 meses após a apli cação de cal cário. A aplicação das doses de gesso el evou os teores de cálcio trocável em todo o perfil do solo, cujo efeito foi observado nas duas épocas de amostragem. Notou-se intensa lixiviação de cálcio pel o uso do gesso nas maiores doses, dependendo do tempo da aplicação.

Os teores de magnésio trocável do solo foram aumentados com a calagem e reduzidos com a aplicação de gesso, até $10 \mathrm{~cm}$ de profundidade 


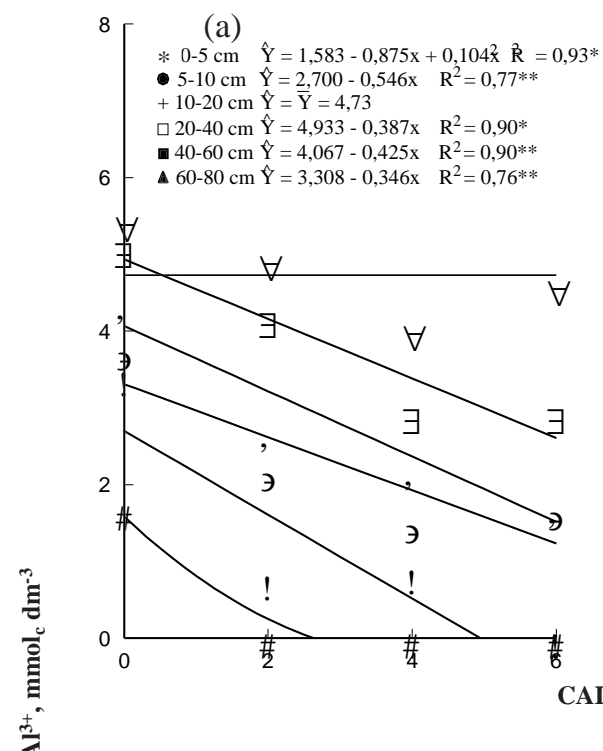

(c)

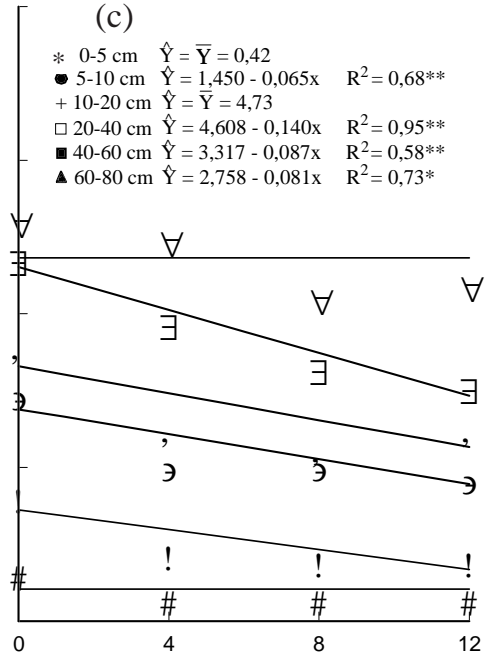

(b)

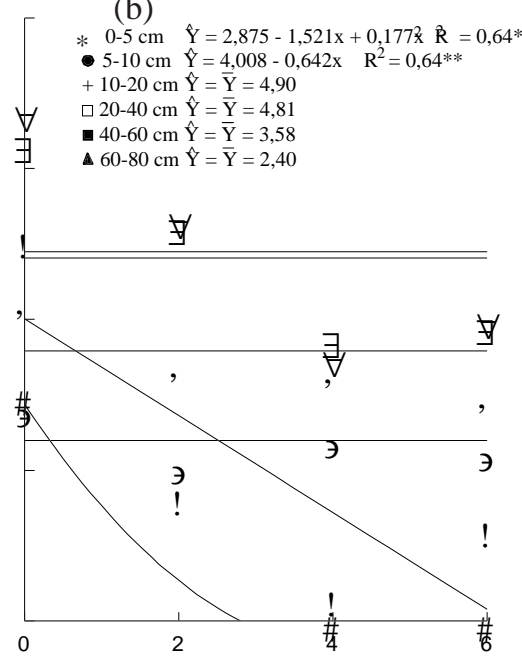

ALCÁRIO, $\mathrm{t} \mathrm{ha}^{-1}$

(d)

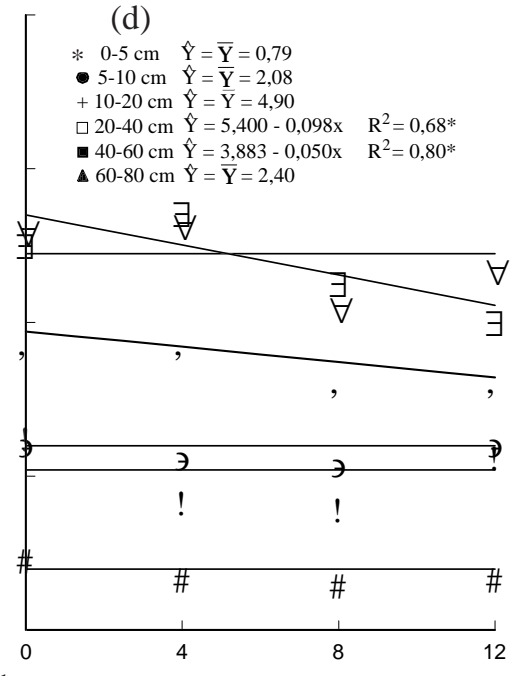

GESSO, $\mathrm{t} \mathrm{ha}^{-1}$

Figura 2. Efeito de doses de calcário, após 18(a) e 40(b) meses, e de gesso, após 14(c) e 36(d) meses, nos teores de Al trocável, em diferentes profundidades. (a e b: médias de quatro doses de gesso; c e d: médias de quatro doses de calcário). *, ** significativos a 5 e 1\%, respectivamente.

(Figura 4). Observa-se que a lixiviação de magnésio nas camadas superficiais do solo foi quase proporcional à el evação deste ocasionada pela calagem. Após 40 meses, verificou-se que a calagem aumentou os teores de magnésio atéa profundidade de $40 \mathrm{~cm}$. Houve, portanto, movimentação lenta e gradual do magnésio, proveniente do calcário, no perfil do solo, em função do tempo de sua aplicação na superfície. O gesso, após 36 meses, continuou provocando lixiviação de magnésio, inclusive em mai ores profundidades $(10-20$ e $40-60 \mathrm{~cm})$. Ressaltase que a lixiviação de magnésio tem sido uma resposta freqüente nos estudos com aplicação de gesso em sol os (Carvalho et al., 1986; Syed-Omar \& Sumner, 1991). A figura 5 evidencia a lixiviação de magnésio trocável do solo causada por tratamentos extremos de gesso, na maior dose de calcário. A aplicação de gesso, em combinação com a calagem, embora possa causar melhoria na distribuição do magnésio proveniente do calcário no perfil do solo, dependendo da dose de gesso utilizada e do tempo decorrido de sua aplicação, pode causar lixiviação muito intensa, reduzindo o teor de magnésio trocável em todo o perfil do solo. Perdas de magnésio provocadas pel o uso de gesso na presença de cal cário também foram observadas por Caires et al. (1998).

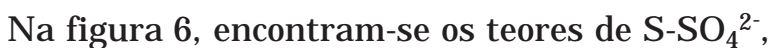
após 40 meses da calagem e 36 meses da aplicação do gesso. Nota-se que os teores de $\mathrm{S}_{-} \mathrm{SO}_{4}{ }^{2-}$ foram reduzidos na camada de $0-5 \mathrm{~cm}$ e aumentados no subsolo (40-60 e 60-80 cm), com a aplicação de cal cário. Como o aumento do pH aumenta a retenção de cálcio e diminui a de sulfato (Camargo \& Raij, 1989), este efeito deve ter sido ocasionado pela 


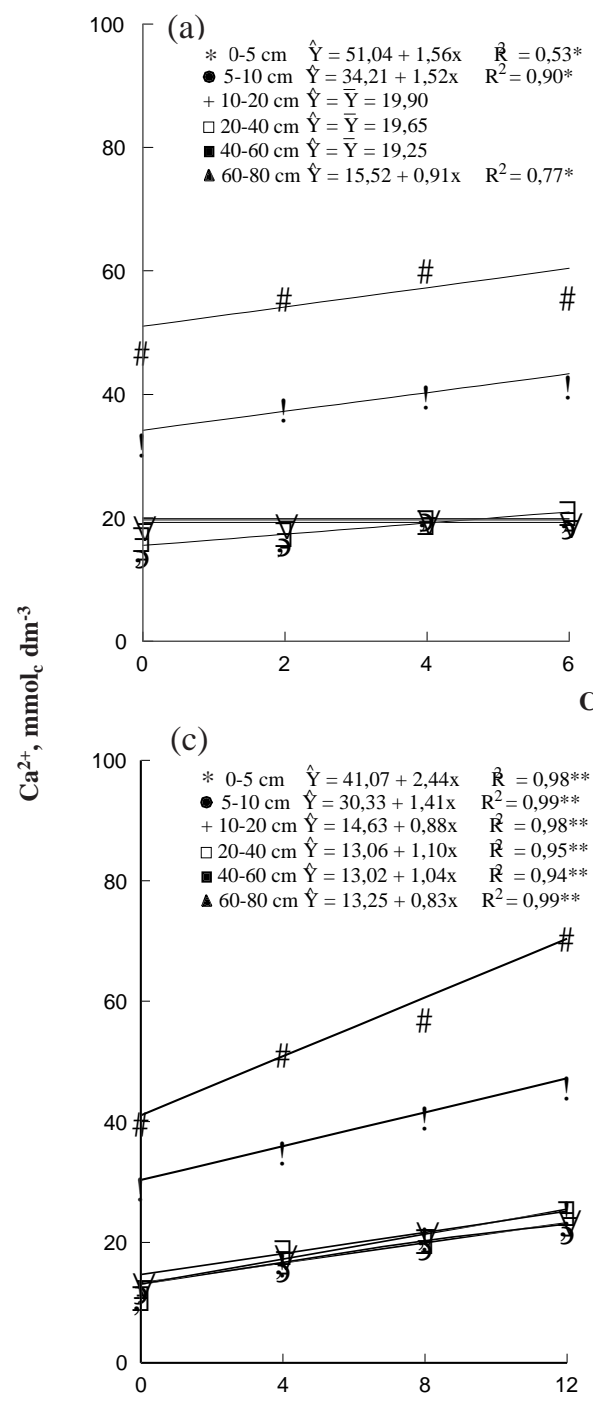

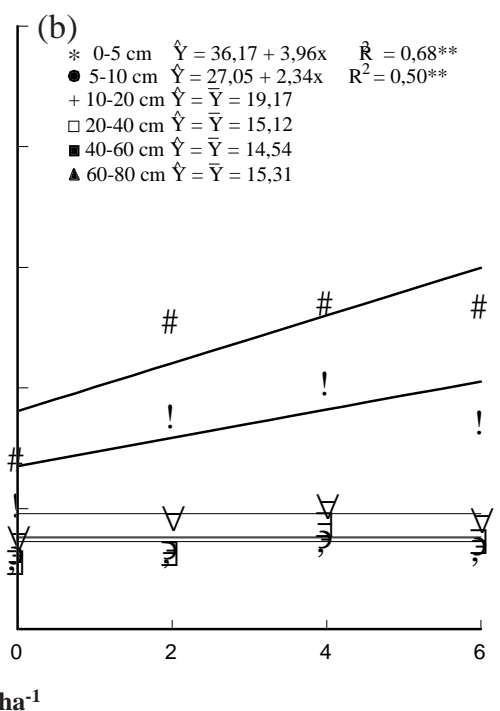

(d)

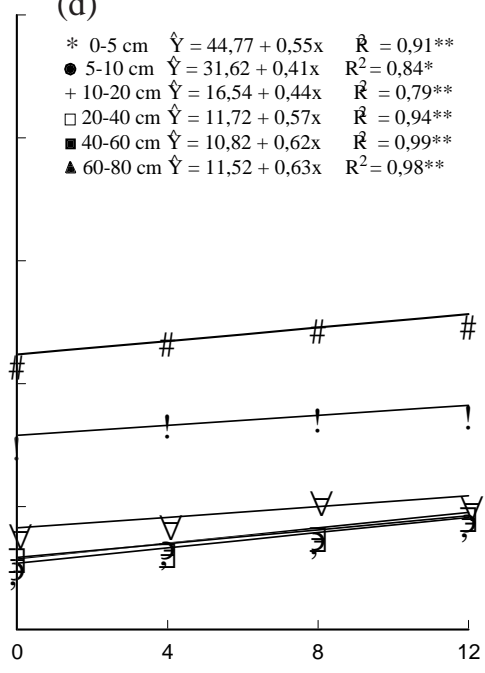

GESSO, $\mathrm{t} \mathrm{ha}^{-1}$

Figura 3. Efeito de doses de calcário, após 18(a) e 40(b) meses, e de gesso, após 14(c) e 36(d) meses, nos teores de Ca trocável, em diferentes profundidades. (a e b: médias de quatro doses de gesso; c e d: médias de quatro doses de calcário). *, ** significativos a 5 e 1\%, respectivamente.

liberação do sulfato adsorvido, em decorrência da elevação do $\mathrm{pH}$ da camada superficial do solo pela calagem. Esses resultados concordam com as indicações de Couto et al. (1979) e Camargo \& Raij (1989) de que a adição de cal cário pode mel horar o movimento de sulfato no solo. Os teores de $\mathrm{S}_{-} \mathrm{SO}_{4}{ }^{2-}$ aumentaram em todo o perfil do solo com a aplicação de doses de gesso, tendo ocorrido mai or acúmulo nas profundidades de 40-60 e $60-80 \mathrm{~cm}$. Houve, portanto, efeito residual da aplicação de gesso, mesmo após 36 meses, apesar da intensa movimentação deS- $\mathrm{SO}_{4}{ }^{2-}$ e de cál cio observada. Quaggio et al. (1993) verificaram que 18 meses após a aplicação de $6 \mathrm{t}$ ha-1 de gesso, com incorporação, em um Latossolo Vermel ho-Escuro podzólico, praticamente todo o cál cio e $\mathrm{S}-\mathrm{SO}_{4}{ }^{2-}$ foram lixiviados para profundidades maiores do que 40-60 cm, mostrando efeito residual bem menor ao observado neste trabalho, com a aplicação de gesso na superfície.

Os teores foliares de cálcio na cultura da soja foram aumentados de forma quadrática com a calagem elinear com a aplicação de gesso (Figura 7). $\mathrm{Na}$ cultura do trigo, os teores de cálcio nas fol has somente foram aumentados com a utilização de gesso. Houve aumento dos teores foliares de magnésio nas culturas de soja etrigo com a aplicação de calcário, bem como redução dos teores na soja com o uso de gesso. O efeito do gesso na redução do magnésio nas fol has de soja também foi observado em outros trabalhos (Oliveira \& Pavan, 1994; Caires et al., 1998) pela lixiviação do magnésio trocável do solo. $\mathrm{O}$ fato de apenas a soja ter sido influenciada por esta lixiviação decorre da mai or exigência dessa cultura ao magnésio presente nas camadas 


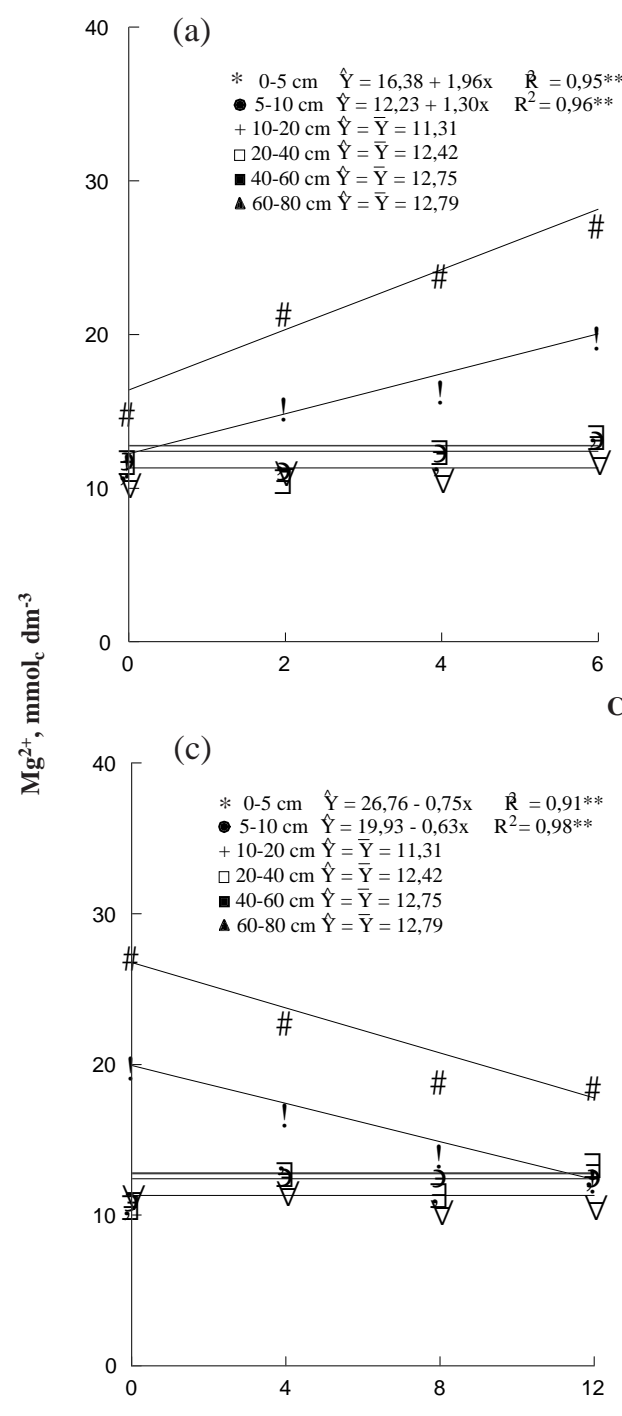

(b)

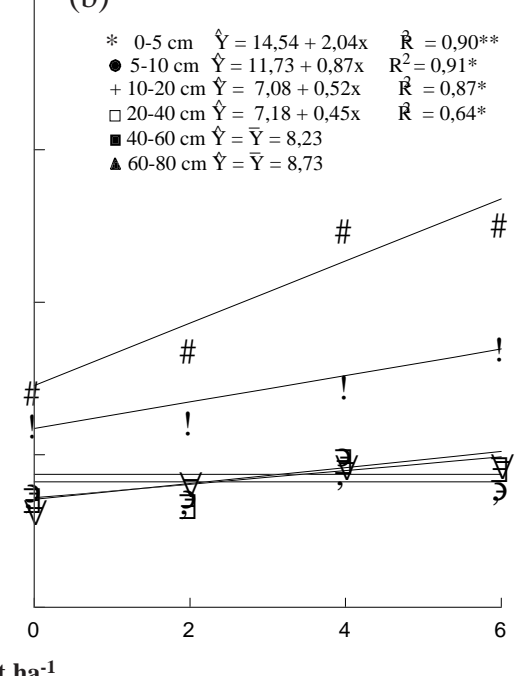

(d)

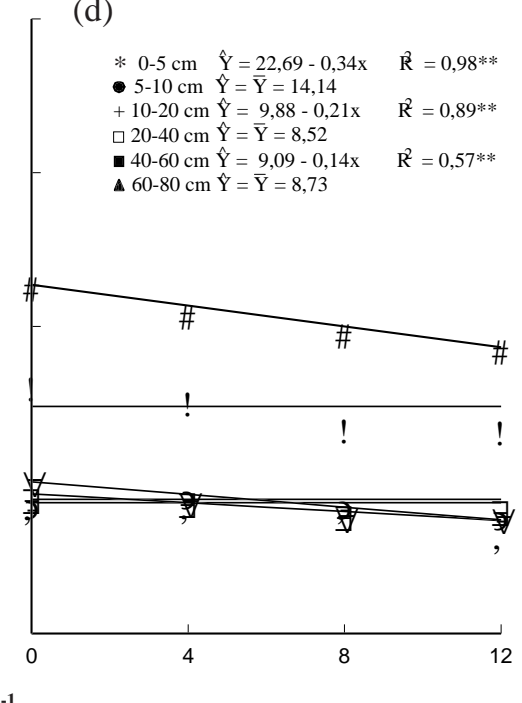

Figura 4. Efeito de doses de calcário, após 18(a) e 40(b) meses, e de gesso, após 14(c) e 36(d) meses, nos teores de Mg trocável, em diferentes profundidades. (a e b: médias de quatro doses de gesso; c e d: médias de quatro doses de calcário). *, ** significativos a 5 e 1\%, respectivamente.

superficiais do solo e de sua menor habilidade de aproveitamento desse nutriente do subsolo, em relação ao milho e ao trigo. A calagem não exerceu influência sobre os teores de enxofre nas fol has das três culturas. Somente a cultura do mil ho apresentou aumento dos teores foliares de enxofre com a aplicação de gesso.

A análise de correlação entre os teores de cálcio nas folhas de trigo e soja e no solo, em função da profundidade (Quadro 2), mostra que o aumento do teor de cál cio nas fol has de trigo, pela aplicação de gesso (Figura 7), deveu-se ao aumento do cál cio trocável no subsolo (40-60 e 60-80 cm). Na cultura da soja, o aumento dos teores foliares de cál ci o ocorreu por causa do aumento do cálcio trocável em todo o perfil do solo, em função do efeito da calagem, até 10 cm, edogesso, até80 cm (Figura 3). Esses resul tados mostrama importância da mel horia dosteores decálcio do subsolo para a absorção de cál cio pelas plantas.

O aumento dos teores de magnésio nas fol has de trigo pela calagem (Figura 7) foi ocasionado pela el evação dos teores de magnésio trocável do sol o nas profundidades de 0-5, 10-20 e 20-40 cm (Quadro 2). No caso da soja, o aumento dos teores de magnésio pela calagem ea redução dos teores pela aplicação de gesso foram decorrentes, respectivamente, da elevação eda lixiviaçãonas camadas de 0-5 e $10-20$ cm.

A produção de grãos de milho, trigo e soja não foi influenciada pela aplicação de cal cário na superfície (Figura 8). Apesar da ausência de resposta das culturas à calagem, resultados deste tipo têm sido observados com certa freqüência, quando se trata de aplicação de cal cário na superfície, em sistema 


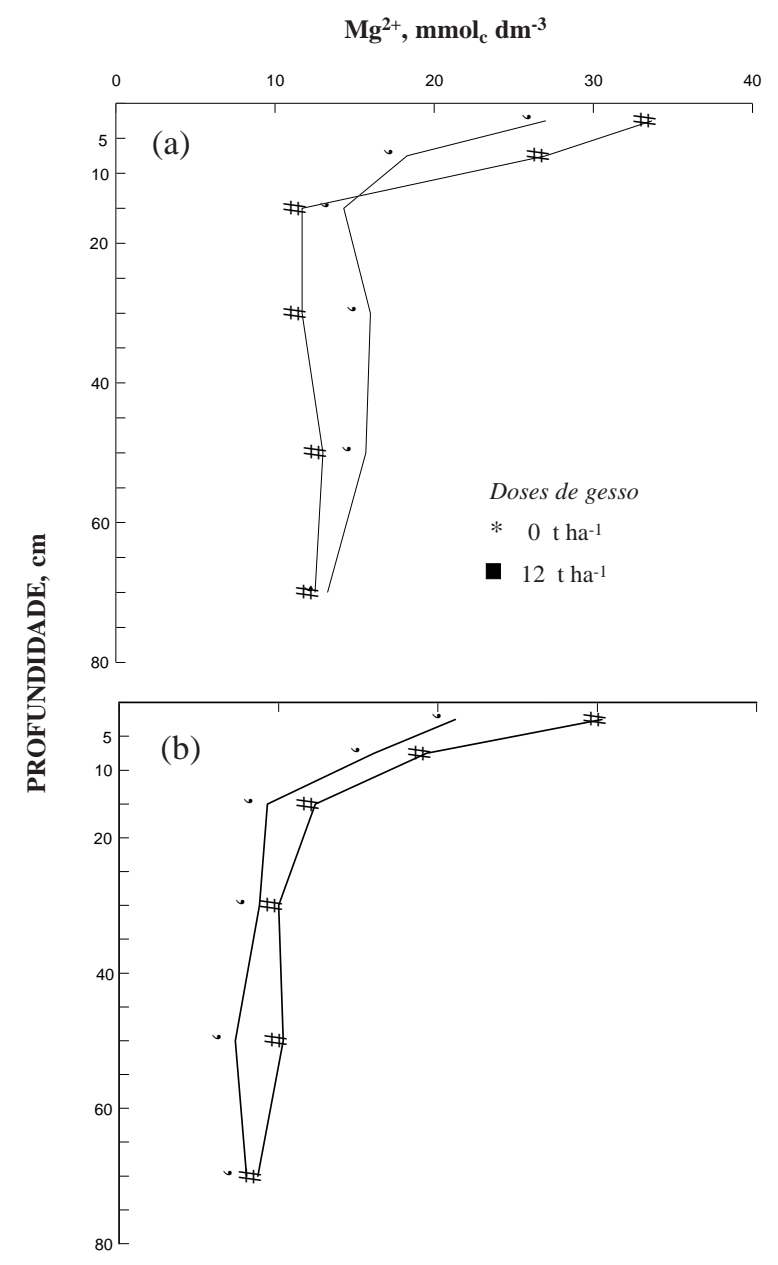

Figura 5. Efeito de doses de gesso sobre o teor de Mg trocável no solo após 14(a) e 36(b) meses de sua aplicação, na dose de $6 \mathrm{t}$ ha ${ }^{-1}$ de calcário. plantio direto. Dados obtidos por Pöttker, 1996 citado por Wiethölter (1997), mostraram que as culturas de soja, trigo e milho cultivadas em sistema de rotação não apresentaram aumento na produção de grãos, a partir da aplicação, na superfície, de 1/4 da dose indicada pelo método SMP para pH 6,0, em sol os com acidez ainda maior à do presente trabal ho. A menor resposta das culturas à calagem no sistema plantio direto pode estar relacionada com o menor efeito tóxico do alumínio, decorrente da formação de compl exos orgânicos solúveis presentes nos restos das plantas (Miyazawa et al.,1996), ou com o fato de os teores de cálcio, magnésio epotássio opresentarem disponibilidade suficiente no perfil do solo para manter uma relação adequada com o alumínio (Caires et al., 1998).

A aplicação de doses de gesso proporcionou aumento na produção somente da cultura do milho, com resposta quadrática (Figura 8). De acordo com a curva ajustada, a máxima produção de milho seria obtida com a dose de 9,5 t ha-1 de gesso, proporcionando aumento na produção da ordem de $1.100 \mathrm{~kg} \mathrm{ha}-1$. A produtividademédia do experimento foi cerca de $10.000 \mathrm{~kg} \mathrm{ha}^{-1}$ de milho. A correlação entre os teores foliares de enxofre e a produção de grãos de milho $\left(r=0,54^{*}\right)$ indica que houve resposta do milho ao aumento dos teores de $\mathrm{S}-\mathrm{SO}_{4}{ }^{2-}$ no solo, devido ao fornecimento de enxofre pelo gesso. Entretanto, a redução da saturação por alumínio (10-20, 40-60 e 60-80 cm), o aumento dos teores de cálcio trocável no perfil do solo e o aumento da relação Ca/Mg (0-5, 5-10 e 20-40cm) contribuíram também para esseaumento de produção (Quadro 3).

É importante ressaltar que a produção de milho não foi influenciada pelo efeito do gesso no aumento do pH (Figura 1) ena redução dos teores dealumínio
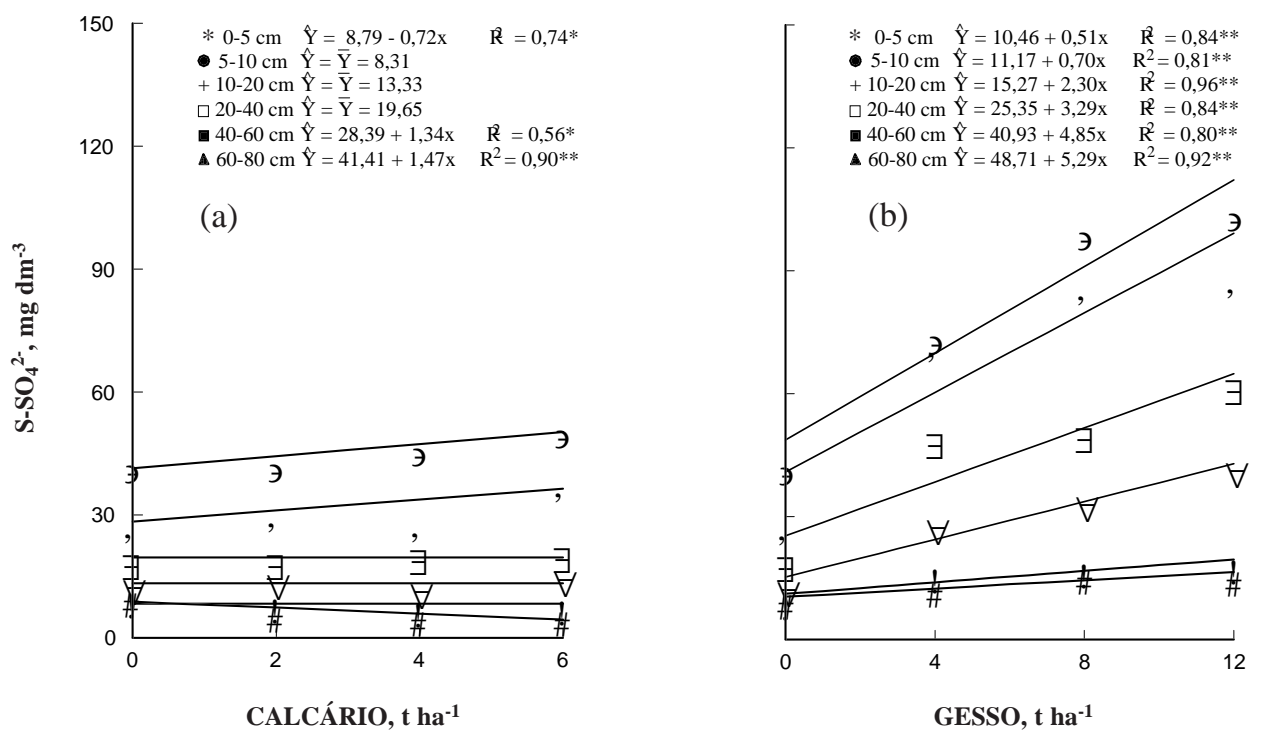

Figura 6. Efeito de doses de calcário, após $\mathbf{4 0}$ meses (a), e de gesso, após 36 meses (b), sobre os teores de $\mathrm{S}-\mathrm{SO}_{4}{ }^{2-}$, em diferentes profundidades. ${ }^{*}, * *$ significativos a 5 e $1 \%$, respectivamente. 
Quadro 2. Coeficientes de correlação entre o teor de cálcio e magnésio nas folhas de trigo e soja e o teor de cálcio e magnésio trocável do solo, em função da profundidade

\begin{tabular}{|c|c|c|c|c|c|c|}
\hline \multirow{2}{*}{ Teor nas folhas } & \multicolumn{6}{|c|}{ Profundidade (cm) } \\
\hline & $0-5$ & $5-10$ & $10-20$ & $20-40$ & $40-60$ & $60-80$ \\
\hline & \multicolumn{6}{|c|}{ Cálcio trocável } \\
\hline & 0,43 & 0,37 & 0,28 & 0,45 & $0,56 *$ & $0,58 * *$ \\
\hline \multirow{2}{*}{ Soja } & $0,57 *$ & $0,51 *$ & $0,49 *$ & $0,68^{* *}$ & $0,68^{* *}$ & $0,70 * *$ \\
\hline & \multicolumn{6}{|c|}{ Magnésio trocável } \\
\hline Trigo & $0,87^{* *}$ & 0,36 & $0,61^{*}$ & $0,50 *$ & 0,45 & 0,46 \\
\hline Soja & $0,59 *$ & 0,41 & $0,56 *$ & 0,41 & 0,27 & 0,21 \\
\hline
\end{tabular}

*, ** significativos a 5 e $1 \%$, respectivamente.

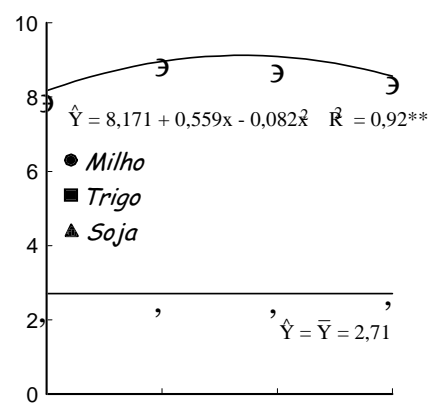

(a)
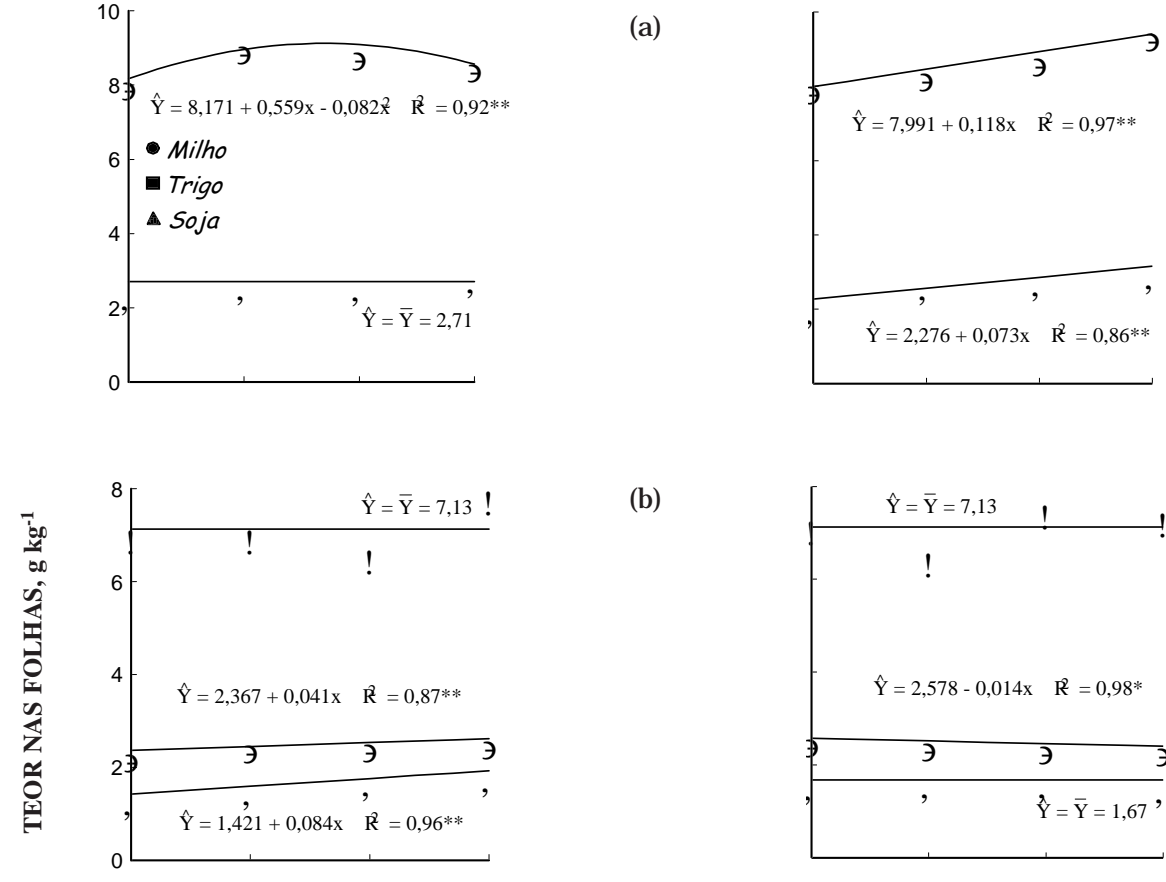

(b)
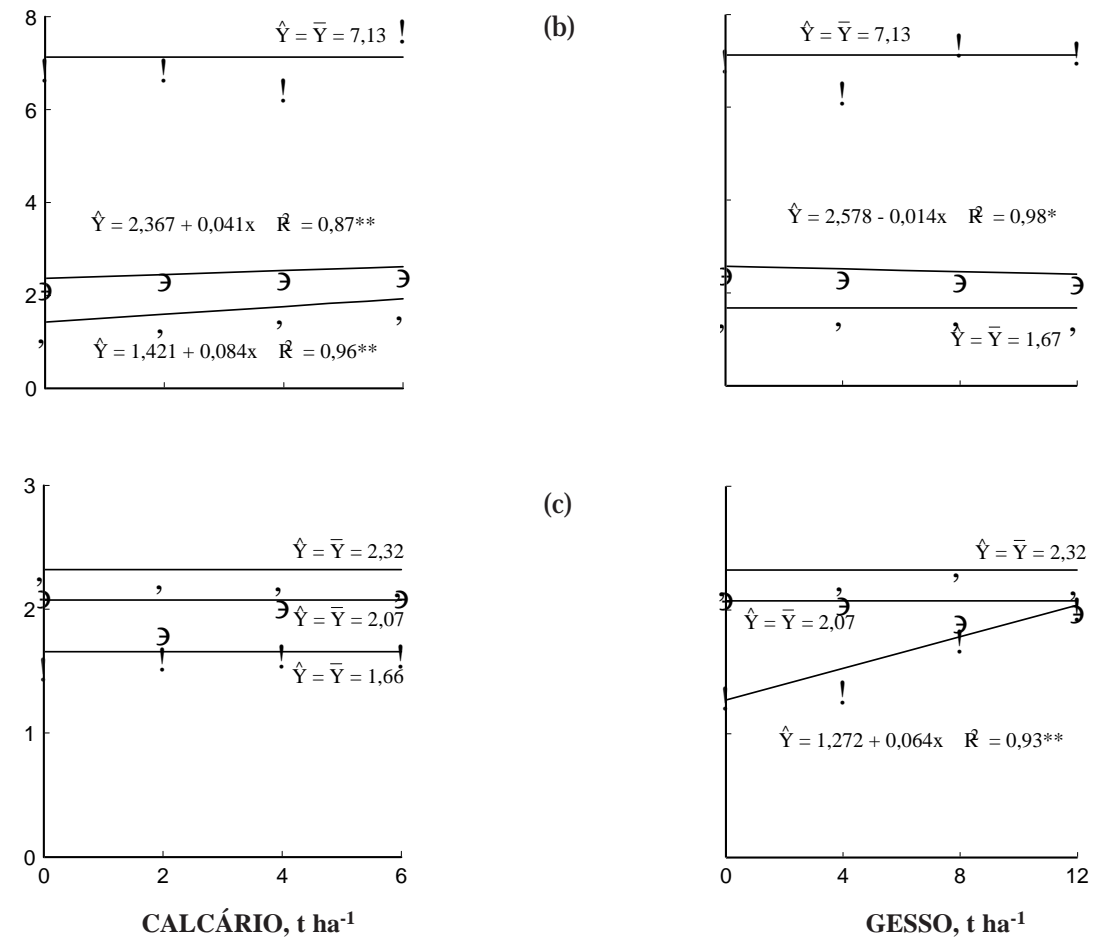

(c)

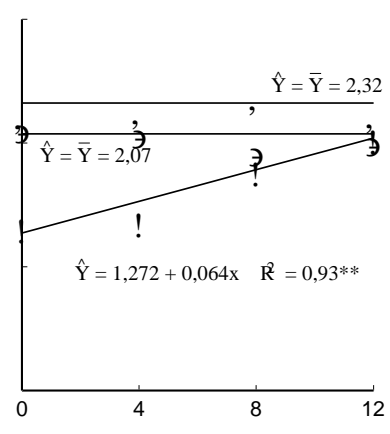

GESSO, $\mathrm{t} \mathrm{ha}^{-1}$

Figura 7. Efeito da calagem e da aplicação de gesso sobre os teores de cálcio (a), magnésio (b) e enxofre (c) nas folhas de milho, trigo e soja. Pontos são médias de quatro doses de calcário ou gesso. *, ** significativos a 5 e 1\%, respectivamente. 

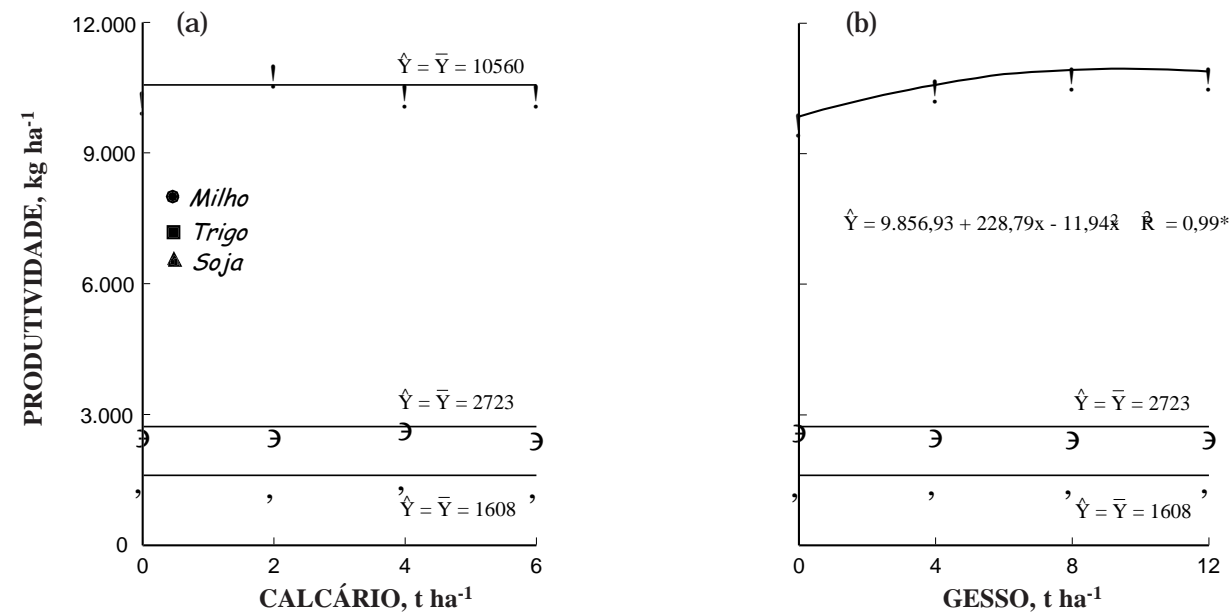

Figura 8. Efeito da calagem (a) e da aplicação de gesso (b) sobre a produção de grãos de milho, trigo e soja. (a: médias de quatro doses de gesso; b: médias de quatro doses de calcário). *significativo a $5 \%$.

trocável do subsolo (Figura 2). A cultura do milho tem apresentado respostas positivas ao uso de gesso, nas mais diversas condições desol o e clima. É o caso dos resultados obtidos por Furlani et al., 1992 citados por Quaggio (1992), em Latossolo Vermel ho-Escuro álico textura argilosa do estado de São Paulo; por Peruzzo et al. 1990 e Bianchi et al., 1990 citados por Ernani et al. (1992), respectivamente, em L atossolo Vermelho-Escuro distrófico e Podzólico VermelhoEscuro do Rio Grande do Sul; por Sousa et al. (1992), em Latossolo de cerrado do Brasil Central, e por Farina \& Channon (1988), em um Ultisol da África doSul. Nesses trabal hos, as doses de gesso variaram de 2 a 10 t ha-1 e os ganhos médios na produção de grãos de milho foram de 9 a 82\%. As maiores respostas do milho sempre foram observadas em condições de déficit hídrico, o que não ocorreu no presente trabalho. No caso da cultura da soja, a maioria dos trabalhos tem mostrado ausência de resposta ao gesso aplicado (Peruzzo et al., 1990 e Daein et al., 1991 citados por Ernani et al., 1992;
Nunes \& Eichler, 1988; Vasconcelos et al., 1990; citados por Sousa et al., 1992; Quaggio et al., 1993; Caires et al., 1998), concordando com os resultados obtidos. Para a cultura do trigo, existem trabalhos mostrando desdeausência de resposta (Daein et al., 1991 citados por Ernani et al., 1992) até aumentos da ordem de $50 \%$ na produção de grãos, pelo uso de gesso, mesmo em condições de suprimento adequado de água (Sousa et al., 1985 citados por Sousa et al., 1992). Deve-se ressaltar, no presente trabalho, grande preci pitação pluvial na época da col heita de trigo, o que resultou em coeficientes de variação relativamente el evados (parcela $=35 \%$ e subparcela $=17 \%$ ), decorrentes das perdas ocorridas.

\section{CONCLUSÕES}

1. O cal cário aplicado na superfície, em sistema plantio direto, apresentou eficiência na correção da acidez das camadas superficiais esubsuperficiais do

Quadro 3. Coeficientes de correlação entre a produção de milho e as características da fertilidade do solo, em função da profundidade

\begin{tabular}{cccccc}
\hline Profundidade & $\mathbf{p H}\left(\mathbf{C a C l}_{\mathbf{2}}\right)$ & Al trocável & $\mathbf{m}$ & Ca trocável & Relação Ca/Mg \\
\hline $\mathrm{cm}$ & & & & & \\
$0-5$ & 0,03 & $-0,32$ & $-0,37$ & $0,60^{*}$ & $0,56^{*}$ \\
$5-10$ & 0,18 & $-0,36$ & $-0,36$ & $0,66^{* *}$ & $0,61^{*}$ \\
$10-20$ & 0,09 & $-0,40$ & $-0,66^{* *}$ & $0,69^{* *}$ & 0,46 \\
$20-40$ & 0,23 & $-0,30$ & $-0,45$ & $0,55^{*}$ & $0,60^{*}$ \\
$40-60$ & 0,21 & $-0,37$ & $-0,52^{*}$ & $0,55^{*}$ & 0,44 \\
$60-80$ & 0,18 & $-0,45$ & $-0,58^{*}$ & $0,53^{*}$ & 0,21 \\
\hline
\end{tabular}

*, ** significativos a 5 e $1 \%$, respectivamente. 
solo, não exercendo influência na produção de milho, trigo e soja, em solo com el evada acidez.

2. É necessário o estabelecimento de critérios específicos à recomendação de calagem no sistema plantio direto.

3. O gesso foi eficiente na melhoria do ambiente radicular do subsolo, causando el evação do $\mathrm{pH}$, redução do alumínio trocável e aumento do cálcio e do sulfato, embora tenha provocado lixiviação do magnésio trocável do solo.

4. Somente a cultura do milho apresentou aumento de produção com a aplicação de gesso em decorrência do fornecimento de enxofre, da mel horia do teor de cálcio trocável em todo o perfil do solo, da redução da saturação por alumínio e do aumento da relação Ca/Mg do solo.

\section{LITERATURA CITADA}

ADAMS, F. \& RAWAYFIH, Z. Basalumiteand alumite: A possible cause of sulfate retention by acid soils. Soil Sci. Soc. Am. J ., 41:686-692, 1977.

ALVA, A.K.; SUMNER, M.E. \& MILLER, W.P. Reactions of gypsum or phosphogypsum in weathered acid subsoils. Soil Sci. Soc. Am. J ., 54:993-998, 1990.

BANZATO, D.A. \& KRONKA, S.N. Experimentação agrícola. J aboticabal, FUNEP, 1989. 247p.

CAIRES, E.F.; CHUEIRI, W.A.; MADRUGA, E.F. \& FIGUEIREDO, A. Alterações de características químicas do sol o e resposta da soja ao cal cário e gesso aplicados na superfície em sistema de cultivo sem preparo do solo. R. Bras. Ci. Solo, 22:27-34, 1998.

CAMARGO, O.A. \& RAIJ , B. van. Movimento do gesso em amostras de Latossolos com diferentes propriedades eletroquímicas. R. Bras. Ci. Solo, 13:275-280, 1989.

CARVALHO, L.J.C.B.; GOMIDE, R.L.; RODRIGUES, G.C.; SOUZA, D.M.G. \& FREITAS, E. Resposta do milho à aplicação de gesso e déficit hídrico em solo de cerrados. In: SEMINÁRIO SOBRE O USO DE FOSFOGESSO NA AGRICULTURA, 1., Brasília, 1986. Anais. Brasília, EMBRAPA-DDT, 1986. p.61-83.

CHANG, M.L. \& THOMAS, G.W. A suggested mechanism for sulfate adsorption by soils. Proc. Soil Sci. Soc. Am., 27:281283, 1963.

COUTO, W.; LATHWELL, D.J . \& BOULDIN, D.R. Sulfate sorption by two Oxisols and Alfisol of the tropics. Soil Sci., 127:108-116, 1979.

ERNANI, P.R.; CASSOL, P.C. \& PERUZZO, G. Eficiência agronômica do gesso agrícola no sul do Brasil. In: SEMINÁRIO SOBRE O USO DO GESSO NA AGRICULTURA, 2., Uberaba, 1992. Anais. Uberaba, IBRAFOS, 1992. p.263-276.

FARINA, M.P.W. \& CHANNON, P. Acid-subsoil amelioration. II Gypsum effects on growth and subsoil chemical properties. Soil Sci. Soc. Am. J ., 52:175-180, 1988.
HUE, N.V.; CRADDOCK, G.R. \& ADAMS, F. Effect of organic acids on aluminum toxicity in subsoils. Soil Sci. Soc. Am. J ., 50:28-34, 1986

MALAVOLTA, E.; VITTI, G.C. \& OLIVEIRA, S.A. Avaliação do estado nutricional das plantas: princípios e aplicações. Piracicaba, POTAFOS, 1989. 201p.

MIYAZAWA, M.; CHIERICE, G.O. \& PAVAN, M.A. Amenização da toxicidade de alumínio às raízes de trigo pela complexação com ácidos orgânicos. R. Bras. Ci. Solo, 16:209215, 1992.

MIYAZAWA, M.; PAVAN, M.A. \& SANTOS, J.C.F. Effects of addition of crop residues on the leaching of $\mathrm{Ca}$ and $\mathrm{Mg}$ in Oxysols. In: INTERNATIONAL SYMPOSIUM ON PLANTSOIL INTERACTIONS AT LOW pH, 4., Belo Horizonte, 1996. Abstracts. Belo Horizonte, Sociedade Brasileira de Ciência do Solo/ EMBRAPA-CPAC, 1996. p.8.

NOGUEIRA, A.R.A. Caracterização fisico-química dos efeitos de tratamentos com cal cário e gesso em al guns sol os de cerrado do estado de São Paulo. São Carlos, Universidade de São Paulo, 1985. 106p. (Tese de Mestrado)

OATES, K.M. \& CALDWELL, A.G. Use of by product gypsum to alleviate soil acidity. Soil Sci. Soc. Am. J ., 49:915-918, 1985.

OLIVEIRA, E.L. \& PAVAN, M.A. Redução da acidez do solo pelo uso de calcário e gesso e resposta da soja cultivada em plantio direto. In: REUNIÃO BRASILEIRA DE FERTILIDADE DO SOLO E NUTRIÇÃO DE PLANTAS, 21., Petrolina, 1994. Anais. Petrolina, Sociedade Brasileira de Ciência do Solo/ EMBRAPA-CPATSA, 1994. p.178.

PAVAN, M.A.; BINGHAM, F.T. \& PRATT, P.F. Toxicity of aluminium to coffe in Ultisol and Oxisols amended with $\mathrm{CaCO}_{3}$ and $\mathrm{CaSO}_{4}$. Soil Sci. Soc. Am. J ., 46:1201-1207, 1982.

PAVAN, M.A.; BINGHAM, F.T. \& PRATT, P.F. Redistribution of exchangeable calcium, magnesium and aluminum following lime or gypsum aplications to a Brazilian Oxisol. Soil Sci. Soc. Am. J ., 48:33-38, 1984.

PAVAN, M.A.; BLOCH, M.F.; ZEMPULSKI, H.C.; MIYAZAWA, M. \& ZOCOLER , D.C. Manual de análise química do solo. Londrina, Instituto Agronômico do Paraná, 1991. 33 p.

POLOMSKI, J .; FLUHLER, H. \& BLASER, P. Fluoride-induced mobilization and leaching of organic-matter, iron and aluminum. J . Environ. Qual., 11:452-456, 1982.

QUAGGIO, J.A. Respostas das culturas de milho e soja à aplicação de cal cário, gesso e movimentação de íons em sol os do estado de São Paulo. In: SEMINÁRIO SOBRE O USO DO GESSO NA AGRICULTURA, 2., Uberaba, 1992. Anais. U beraba, IBRAFOS, 1992. p.241-262.

QUAGGIO, J .A.; RAIJ , B. van; GALLO, P.B. \& MASCARENHAS, H.A.A. Respostas da soja à aplicação de cal cário e gesso e lixiviação de íons no perfil do solo. Pesq. Agropec. Bras., 28:375-383, 1993.

RAIJ , B. van. Reações de gesso em sol os ácidos. In: SE MINÁRIO SOBRE O USO DO GESSO NA AGRICULTURA, 2., Uberaba, 1992. Anais. U beraba, IBRAF OS, 1992. p.105-119. 
RAIJ , B. van; CANTARELLA, H. \& FURLANI, P.R. Efeito, na reação do solo, da absorção de amônio e nitrato pelo sorgo, na presença ena ausência degesso. R. Bras. Ci. Solo, 12:131136, 1988.

REEVE, N.G. \& SUMNER, M.E. Amelioration of subsoil acidity in Natal Oxisols by leaching of surface applied amendments. Agrochemophysica, 4:1-6, 1972.

RITCHEY, K.D.; SILVA, J .E. \& COSTA, U.F. Calcium deficience in clayey B horizons of savannah Oxisols. Soil Sci., 133:378382, 1982.

SINGH, S.J . Effect of chloride and sulfate anions on the chemical characteristics of some acid soils. Can. J . Soil Sci., 62:549557, 1982.

SOUSA, D.M.G.; LOBATO, E.; RITCHEY, K.D. \& REIN, T.A. Resposta de culturas anuais e leucena a gesso no Cerrado. In: SEMINÁRIO SOBRE O USO DO GESSO NA AGRICULTURA, 2., U beraba, 1992. Anais. Uberaba, IBRAFOS, 1992. p.277-306.
SUMNER, M.E. Amelioration of subsoil acidity with minimum disturbance. In: J AYAWARDANE, N.S. \& STEWART, B.A., eds. Subsoil management techniques. Athens, Lewis Publishers, 1995. p.147-185.

SUMNER, M.E.; SHAHANDEH, H.; BOUTON, J . \& HAMMEL, $J$. Amelioration of an acid soil prolife through deep liming an surface aplication of gypsum. Soil Sci. Soc. Am. J., 50:1254-1278, 1986.

SYED-OMAR, S.R. \& SUMNER, M.E. Effect of gypsum on soil potassium and magnesium status and growth of alfafa. Comm. Soil Sci. Plant Anal., 22:2017-2028, 1991.

VITTI, G.C. \& SUZUKI,J .A. A determinação do enxofre- sulfato pelo método turbidimétrico. J aboticabal, Universidade Estadual de São Paulo, 1978. 13p. (Apostila)

WIETHÖLTER, S. Histórico e perspectivas da prática de calagem no Brasil. In: CONGRESSO BRASILEIRO DE CIÊNCIA DO SOLO, 26., Rio deJ aneiro, 1997. Anais. Rio deJ aneiro, Sociedade Brasileira de Ciência do Solo, 1997. (CD-ROM) 